\title{
INTERSTATE DIFFERENCES IN PER CAPITA STATE AND LOCAL REVENUES AND THE NEIGHBORING STATE EFFECT
}

\author{
Kevin J. Murphy and Oded Izraeli*
}

\begin{abstract}
This paper examines cross-state differences in the responsiveness of per capita state and local revenues to changes in factors that determine these revenues. Our model proceeds from two intuitive points of departure. First, because of differing tastes and attitudes among the population toward public goods and services, states should respond differently to underlying determinants of per capita revenues. Second, though states differ generally from one another, groups or pockets of states may behave in a similar fashion because of what the literature has come to refer to as the neighboring state effect. Our data cover the period 1960 to 1992 . The econometric results indicate that states differ in their response to changes in underlying revenue determinants. We also find, however, that some states exhibit a considerable degree of neighboring state behavior, particularly in the New England, West North Central, West South Central, and Mountain regions.
\end{abstract}

\section{INTRODUCTION}

Revenues collected by state and local governments ${ }^{1}$ vary considerably on a per capita basis by state. For example, 1990 per capita state and local revenues from own sources had a standard deviation of $\$ 877.34$ and ranged from a low of $\$ 1,411$ in Arkansas to highs of $\$ 3,225$ in New York and \$7,666 in Alaska. This paper explores the factors accounting for the wide differences observed in this variable across states.

Our study proceeds to address the question using two intuitive observations as points of departure. First, the factors that generally determine state and local revenues are likely to have impacts that vary geographically because neither politicians nor citizens are homogeneous across regions. Second, though states are inherently heterogenous, groups or "pockets" of states aren't necessarily heterogenous. Rather, behavior in these pockets with respect to tax policy may be quite similar. This regional homogeneity has been referred to in the literature as the "neighboring state" effect and may result because people in a particular area spanning state boundaries have similar tastes with respect to public goods and services; because the industrial structure is similar in a given region (e.g., the Rustbelt or the Farmbelt); because historical circumstances (such as in the South) have led states to behave similarly; or because public officials in one state emulate the behavior of public officials in other states on matters of tax policy. Our

*Professors of Economics, Oakland University, Rochester, Michigan. 
analysis examines differences across states in sensitivity to factors that determine per capita revenues, but at the same time, it allows for some degree of homogeneity among states at the sub-national level.

Previous studies have examined various aspects of state and local government revenues. ${ }^{2}$ Though these studies have used data from individual states, the general approach has been aggregate in nature. Econometrically, this aggregation forces imposition of a homogeneous coefficient assumption across states. In other words, past investigations have assumed, for example, that changes in per capita income affect state revenues in precisely the same way in states as diverse as, say, New York and Utah or California and South Dakota. This assumption may indeed be appropriate, but it should be tested.

In this study, we employ a data set that allows such testing. The data span the period 1960 to 1992, thus we possess a reasonably long time series for each state in the sample. The econometric methodology we employ permits us not only to ascertain that state and local revenues respond differently to changes in underlying determinants such as per capita income, local labor market conditions, population density, demographic composition, and political orientation of the voting public, but, more importantly, the methodology allows us to group states into smaller homogeneous sub-regions. ${ }^{3}$ This "selective" pooling of states increases econometric efficiency and enables us to explore the importance of the neighboring state effect discussed but that is largely not measured in the previous literature. $^{4}$

The remainder of the paper is organized as follows. Section II discusses the determinants of per capita state and local revenues. Section III describes the selective pooling procedure used to identify neighboring states. Section IV presents the empirical results. Section $\mathrm{V}$ closes the paper with a summary and discusses possible extensions of the work.

\section{THEORY}

States provide their residents with a package of goods and services that includes education, highway construction and maintenance, social welfare and insurance, and police and fire protection. In order to provide these goods and services, state and local governments tax their citizens. Though state and local revenues per capita may differ from one locale to another because some public officials are more acquisitive than others (the Leviathan hypothesis), differences of this nature tend to be held in check by the election process and by mobility of resources (Oates 1985). Fundamentally, revenues differ on a per capita basis be- 
cause of different tastes and needs of the populace. The question, then, is what factors account for these differences in tastes and needs across states?

The foremost determinant of revenue in an area must, of course, be income. ${ }^{5}$ The major sources of financing at the state and local level are the property tax, the sales tax, and the income tax. All three taxes depend on income directly (income $\operatorname{tax})^{6}$ or indirectly (property and sales taxes). ${ }^{7}$ The relationship between income (i.e., the tax base) $)^{8}$ and tax revenues is not necessarily simple. This complexity occurs because the tax structure may change as income changes (possibly in more than one way) and because governments may take discretionary actions when automatic changes are deemed insufficient. ${ }^{9}$ If the relationship between income and tax revenue is positive, it suggests that taxpayers would like to spend more on government goods and services as income rises. Increases in income therefore lead to higher expenditures on education and/or better roads and/or more sophisticated police and fire protection and/or improved environmental quality, and so on.

The question of interest for this study is not so much whether a direct relationship exists between income and tax revenue, but rather how strong the response of tax revenue is to changes in income in different states or in groups of states. ${ }^{10}$ In order to measure the strength of the response, the elasticity of revenue with respect to income will be used. The sign of the elasticity indicates if state and local services are normal (positive) or inferior goods. ${ }^{11}$ The magnitude of the elasticity indicates the change in the proportion of income spent for state and local goods and services as income rises.

Aside from the differing tastes and attitudes toward public goods and services reflected in variation in income level, differences in population composition will imply different levels of demand for public goods and services. A relatively older population, for example, will have different concerns and needs than a younger populace. People in areas prone to higher levels of unemployment may desire more public sector support than those in lower unemployment areas, and so forth. Thus in the empirical work it will be important to control for other tasteshaping influences.

A third factor likely to be of importance in determining per capita revenue is the existence of economies or diseconomies of scale in the provision of public goods and services. Economies of scale may exist because many public goods, by their very nature, have relatively high fixed-cost components (e.g., roads). On similar lines, state and local goods and services should be cheaper to provide in high density areas because of lower transportation costs due to shorter distances and because of possible agglomeration effects. It may be the case, therefore, that densely populated states will be able to deliver a given package of public goods to their residents at a lower individual cost and that this saving will be reflected in lower state and local revenue collected per capita. On the other hand, greater 
population and higher population density may lead to congestion costs and to urban ills such as high crime rates and pollution levels which raise the level of public support needed and, in turn, raise the overall tax price of residence in the state. If the latter effect dominates, then per capita state and local revenue will increase with measures of population size.

Finally, we expect that the behavior of governments in neighboring states determines to some degree the per capita revenue in a given state. While politicians may have their own agendas, they are ultimately responsible to the voting public. Economic agents are able to respond to detrimental or onerous tax policies through at least two channels: voice and exit. The most direct channel through which to effect political change is through the periodic exercise of voice at the voting booth. Public officials wishing to perpetuate their tenure, therefore, must design tax and spending policies that please, or at least do not disenchant, the median voter. Because of similarities in industry mix as well as climate and other natural conditions, information is cheaper and easier to collect close to home; therefore, voters will compare conditions in their own state with tax and spending policies in neighboring jurisdictions. Upon comparison, ${ }^{12}$ if they regard the tax burden to be out of line with that found in nearby states, pressure will build for reform, be it through reform by currently elected officials or be it through a new administration. This periodic review process surely acts as a strong constraint on the tax policies adopted by state and local officials.

The less direct channel of response is exit. For example, high taxes on business and on consumption may generate job loss through an outflow of private sector capital or may dissuade businesses from locating in a state in the first place. Because mobility of factors of production is determined in part by distance, we expect that economic agents, particularly workers and small businesses, will judge their state and local politicians on the basis of the performance of politicians in neighboring locales. In the empirical work below, we model the neighboring state effect as a constraint on the behavior of a state's politicians.

We summarize the foregoing theoretical discussion with the following reduced-form equation for per capita state and local revenues:

$$
\begin{aligned}
& \text { GROSC }_{i t}=f_{i}\left(Y_{i t}, \text { Taste }_{i t}, \text { Scale }_{i t}\right) \\
& \text { where GROSC } \mathrm{C}_{\text {it }} \text { is per capita state and local revenues } \\
& \text { from own sources for state } i \text { in year } t \text {; } \\
& Y_{i t} \text { is state i per capita income in year } t \text {; } \\
& \text { Taste it is a vector of demographic, economic, } \\
& \text { and political variables specific to state } i \\
& \text { reflecting population taste for public goods } \\
& \text { and services; }
\end{aligned}
$$


and Scale it is a vector of variables included to measure possible economy of scale effects on revenues in state $i$.

\section{ECONOMETRIC SPECIFICATION}

Equation (1) subscripts the functional relationship between per capita revenues and the independent variables by state. We believe it is important to do so because the explanatory variables are likely to affect revenues in differing ways from state to state. Such differences arise because tax structures differ across states; e.g., some states rely heavily on regressive sales taxes, while others rely more on proportional or progressive income taxes. In addition, it is unlikely that proxy variables measuring taste in a tax revenue regression will adequately reflect taste differences across states. Therefore, a more flexible functional form will capture such taste differences to a greater degree.

One could estimate equation (1) using a pooled specification, but this imposes a very strong restriction on the regression coefficients that is not likely to be warranted in light of the foregoing arguments. If the restriction is not warranted, then pooling amounts to a specification error similar to the omitted variable problem. In this event, the estimated parameter vector overstates the effects of the explanatory variables in some instances and understates them in others.

We propose the following empirical counterpart to equation (1): ${ }^{13}$

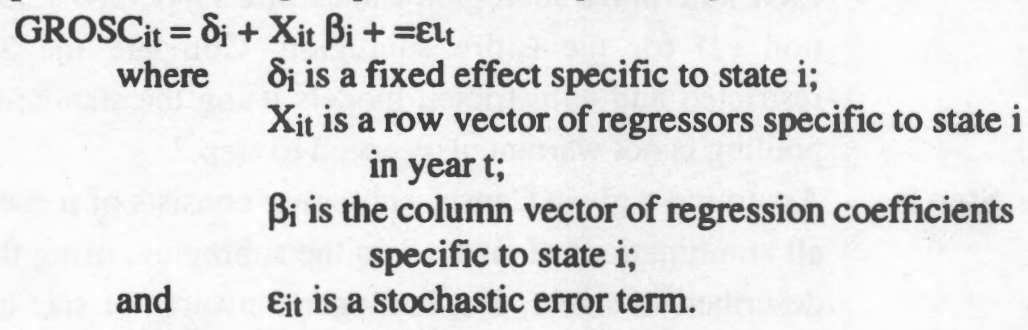

In the preceding section, we raised the possibility that the fiscal behavior of neighboring states constrains the behavior of officials in a given state. An alternative way of expressing this proposition is to say that, to the extent that the neighboring state phenomenon is important, tax revenues in subregions of the economy will respond in similar fashion to changes in the explanatory variables. While identification of such pockets of neighboring states is of interest economically, it also leads to an econometric fringe benefit in that data for states which behave similarly may be pooled, yielding an increase in efficiency of estimation of equation (2). We refer to such pooling as "selective pooling." Thus if two states, $i$ and 
$\mathrm{j}$, are determined to be "neighboring" states, then equation (2) is recast as follows:

$$
\left[\begin{array}{l}
G R O S C_{i} \\
G R O S C_{j}
\end{array}\right]=\left[\begin{array}{l}
X_{i t} \\
X_{j t}
\end{array}\right] \quad \beta+\left[\begin{array}{l}
\varepsilon_{i t} \\
\varepsilon_{j t}
\end{array}\right]
$$

Hence, while pooling the data in general is not likely to be warranted, pooling some of the data not only makes sense on intuitive grounds, but also on econometric grounds.

Many feasible combinations of states exist; the practical question is how to determine which states are neighbors. We adopt the philosophy that geographic proximity is the criterion determining whether or not states are neighbors. ${ }^{14}$ Thus officials in Vermont may look to what New York is doing with respect to taxes but would seem unlikely to look to what New Mexico is doing. Similarly, Indiana may behave like Ohio, but would be unlikely to behave like Oregon. The idea is that a state's citizens and public officials will look to nearby states rather than to areas that are far removed. Information acquisition regarding nearby states is less costly. Moreover, mobility to nearby states is less costly in both pecuniary and non-pecuniary terms.

More formally, in order to identify neighboring states in the empirical analysis below, we utilized the following grouping or "pooling" algorithm: ${ }^{15}$

\section{POOLING ALGORITHM}

Step 1. Group states into Census sub-regions. ${ }^{16}$ Estimate equation (2) for each state in the subregion and estimate a pooled version of equation (2) for the entire subregion. Compare the SSEs of the restricted and unrestricted models using the standard F-test. ${ }^{17}$ If pooling is not warranted, proceed to step 2.

Step 2. Assuming a given Census subregion consists of $\mathrm{n}$ states, consider all combinations of size $n-1$ in the subregion, using the technique described in step 1. If a homogeneous area of size $n-1$ is found, stop and proceed to step 4. If no pooling is warranted at this level, proceed to step 3.

Step 3. Consider all combinations of size $n-2$ in the subregion. If no pooling is warranted at this level, continue comparisons until all combinations down to size 2 have been considered in the subregion.

Step 4. Compare homogeneous areas within a given Census subregion to homogeneous areas in contiguous states ${ }^{18}$ in other Census subregions and to contiguous individual states in other subregions. 
Step 5. Compare unattached states in a given subregion with other unattached but contiguous states outside of the subregion.

\section{DATA AND EMPIRICAL ANALYSIS}

The state and local tax revenue data were drawn from Government Finances, published by the Census Bureau. These data span the period 1960 to 1992 for all 50 states. The dependent variable is real per capita state and local revenue from own sources. ${ }^{19}$

We use real state per capita personal income $(\mathrm{Y})$ as our measure of state income. ${ }^{20,21}$ We employ five variables as proxies for taste factors: percent working age population that is 16-19 years of age (\%Teen); percent of population aged 65 and over (\%Over65); percent working age population that is non-white (\%Nonwhite); state unemployment rate (UR); and percent voting Republican in last presidential election (\%Repub). ${ }^{22}$ In order to measure the possible effect that economies of scale have on per capita state and local revenues, we utilize two variables: state population density (DEN) ${ }^{23}$ and total state population (POP). All of the explanatory variables, with the exception of two of the demographic measures, were drawn from various years of the U.S. Statistical Abstract. \%Teen and \%Non-white come from the Geographic Profile of Employment and Unemployment and from state volumes of the U.S. Census of Population.

\section{A. Discussion of Pooling}

In order to test our contention that equation (1) should not be estimated using a homogeneous specification, we compared the SSE from a pooled version of equation (2) ${ }^{24}$ for all 50 states with the joint SSE from separate regressions for the 50 states. The pooled regression is a fixed effects version of equation (2) that includes a dummy variable for each state respectively (base state is Wyoming), but imposes the constraint that the coefficients of the regressors be homogeneous across states. This specification thus allows for the possibility that factors unmeasured in the independent variable set, such as political idiosyncracies and geographic advantages or disadvantages, have a systematic impact on per capita revenue by state, but forces homogeneity in the ways in which the independent variables affect state revenues. The resulting F-statistic was 8.52 , significant at better than the .01 level; therefore, we reached the hardly surprising conclusion that state and local tax revenues are not determined in identical fashion for all states. 
TABLE 1

Selectively Pooled Subregions: Dependent Variable is GROSC

\begin{tabular}{lccc}
\hline \hline Subregion & $\begin{array}{c}\text { Critical } \\
\text { F-Statistic }\end{array}$ & $\begin{array}{c}\text { Sample } \\
\text { F }\end{array}$ & Size \\
\hline 1. Connecticut, Maine, Vermont & 1.52 & 1.75 & 99 \\
2. Florida, Georgia, North Carolina & 1.62 & 1.75 & 99 \\
3. Indiana, Kentucky, Virginia & 1.64 & 1.75 & 99 \\
4. Iowa, Kansas, Minnesota & 1.61 & 1.75 & 99 \\
5. Montana, New Mexico, Utah & 1.74 & 1.75 & 99 \\
6. Arizona, Colorado & 1.31 & 2.08 & 66 \\
7. Arkansas, Texas & 1.64 & 2.08 & 66 \\
8. California, Nevada & 1.93 & 2.08 & 66 \\
9. Hawaii, Oregon & 1.58 & 2.08 & 66 \\
10. Louisiana, Oklahoma & 1.39 & 2.08 & 66 \\
11. Massachusetts, New Hampshire & 1.94 & 2.08 & 66 \\
12. New Jersey, New York & 1.87 & 2.08 & 66 \\
13. North Dakota, South Dakota & 1.90 & 2.08 & 66 \\
14. Ohio, West Virginia & 0.51 & 2.08 & 66 \\
& & &
\end{tabular}

We next applied the selective pooling procedure. The groupings by state are presented in Table 1 along with the relevant F-statistic, appropriate critical value, and resulting number of observations. In an examination of Table 1, the first question that must be asked is whether there seems to be a lot of subregion homogeneity among the states or only a little. Recognizing that the answer to this question is to some degree in the eye of the beholder, we note that the results, with 33 of the states grouped into larger subregions, indicate that a majority of the states exhibit some degree of neighboring state behavior. On the other hand, a number of individual states bear no resemblance to other geographically proximate states in the mechanism by which tax revenues are determined.

Perusal of Table 1 also reveals some noteworthy regional patterns. For instance, states in the Northeast (New England and Mid-Atlantic), West North Central, West South Central, and Mountain regions all exhibit a fairly high degree of homogeneity. Moreover, three instances exist where states may be grouped with states from outside of their own Census subregion. Thus Indiana (East North Central) is grouped with Kentucky (East South Central) and Virginia (South Atlantic). Similarly, California (Pacific) is grouped with Nevada (Mountain), and Ohio (East North Central) is grouped with West Virginia (South Atlantic). In 
general, Table 1 suggests that neighboring state behavior takes place to one degree or another in all of the census subregions.

\section{B. Regression Estimates}

Table 2 presents the estimated regression parameters for the 14 subregions and the 17 individual states. The table is organized by major Census region. In addition to the coefficient estimates, the table also shows the median coefficient values for all areas and for each major Census region. Durbin-Watson statistics are reported in the last column of the table. Most of the Durbin-Watson statistics are either insignificant or are in the inconclusive region; therefore, in order to maintain comparability across equations we chose not to correct for any possible serial correlation in the residuals in the few cases where it appeared to be warranted. $R^{2}$ s for the regression equations were uniformly high, with only three states or subregions dropping below 95 .

Turning to the regression coefficients themselves and beginning with per capita income, we note that the income elasticity of state and local revenues is generally above one, with a median value of 1.025 , and that it is positive and significant at least the .05 level in all instances except for Delaware, Wisconsin, and Wyoming. That the coefficient on this variable is positive is not surprising, as this reflects the direct or indirect dependence of most state and local revenues on income. What is interesting here, however, is divergence of the estimated coefficient from one. Parameter estimates above one suggest an implicit willingness on the part of taxpayers to set aside proportionally more of their income for public goods and services as income rises. Estimates falling below one suggest that taxpayers, while spending more on public goods and services as income rises, allocate proportionally less of their incomes to this endeavor. The region of the country with the lowest median parameter estimate for this variable is the North Central region. Farmbelt states such as Iowa, Kansas, and Minnesota, the Dakotas, Wisconsin and Nebraska have particularly low income elasticities. States outside of the North Central region with low personal income elasticities include Delaware, Alabama, Mississippi, Arkansas/Texas, and Louisiana/Oklahoma from the South region and Montana/New Mexico/Utah, Arizona/Colorado, Wyoming and Idaho from the Mountain region. Anomalies at the upper end of the spectrum are Alaska, New Jersey/New York, and Illinois, all of which possess income elasticities greater than 1.7.

As expected, variables reflecting taste factors present a mixed bag of results. Percent of the working age population that is teenaged and percent of population aged 65 and over both indicate a direct relationship between state and local tax revenue and the relevant explanatory variable. The median coefficient value of 


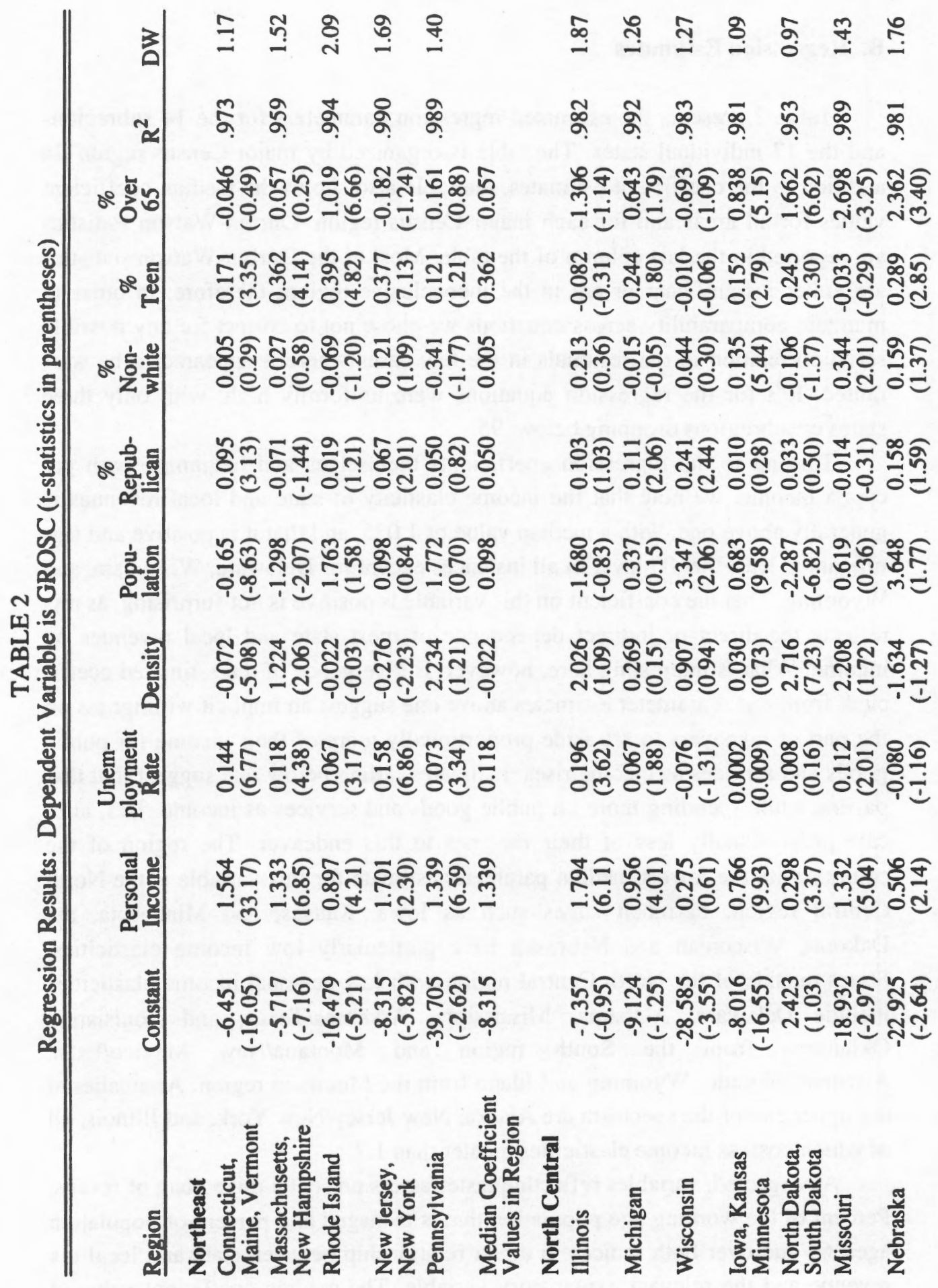




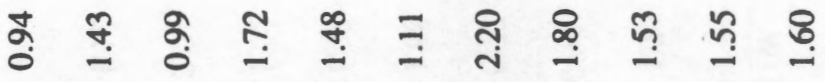

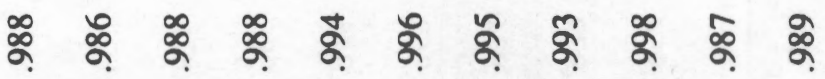

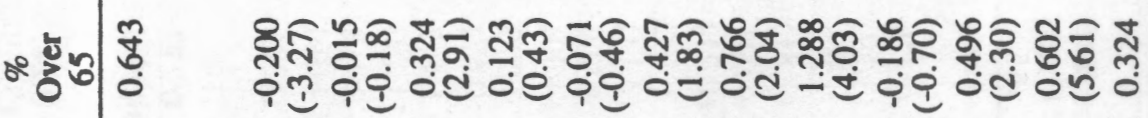

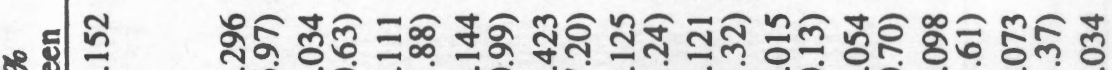

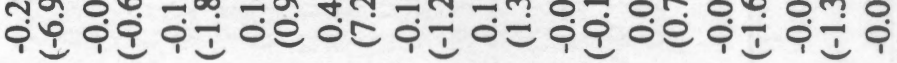

๙

๙

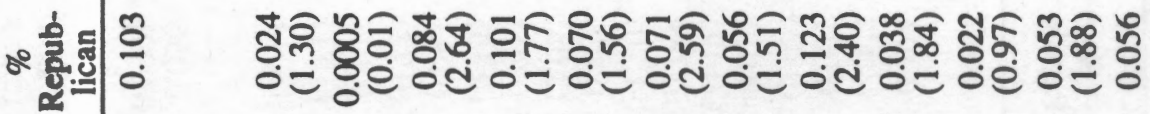

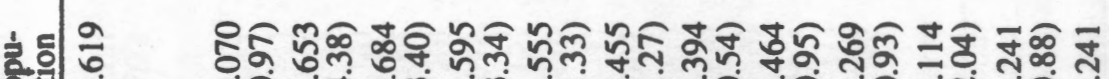

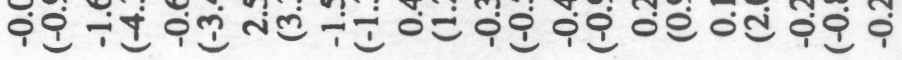

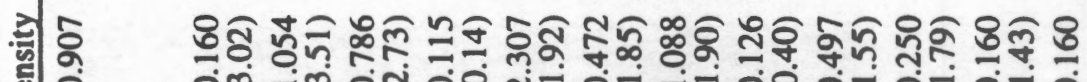



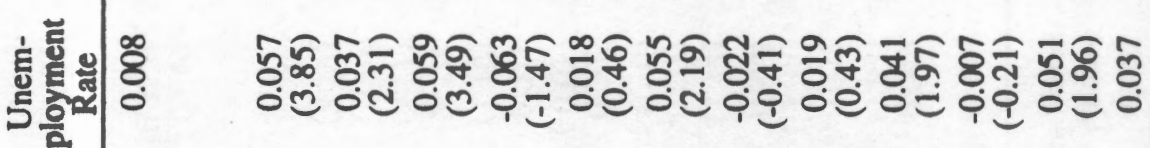

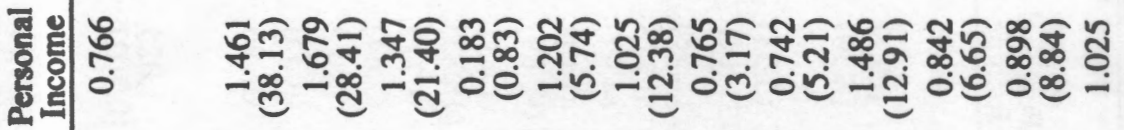

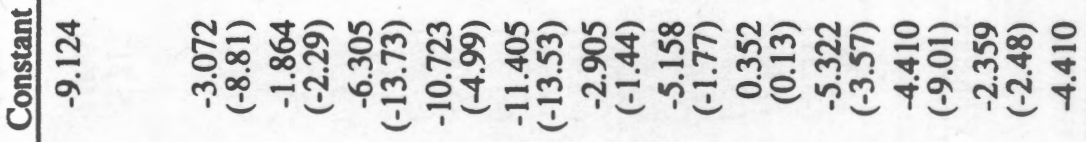

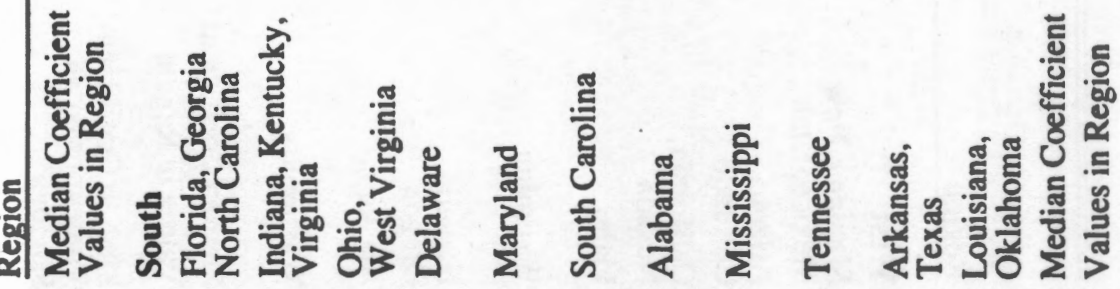




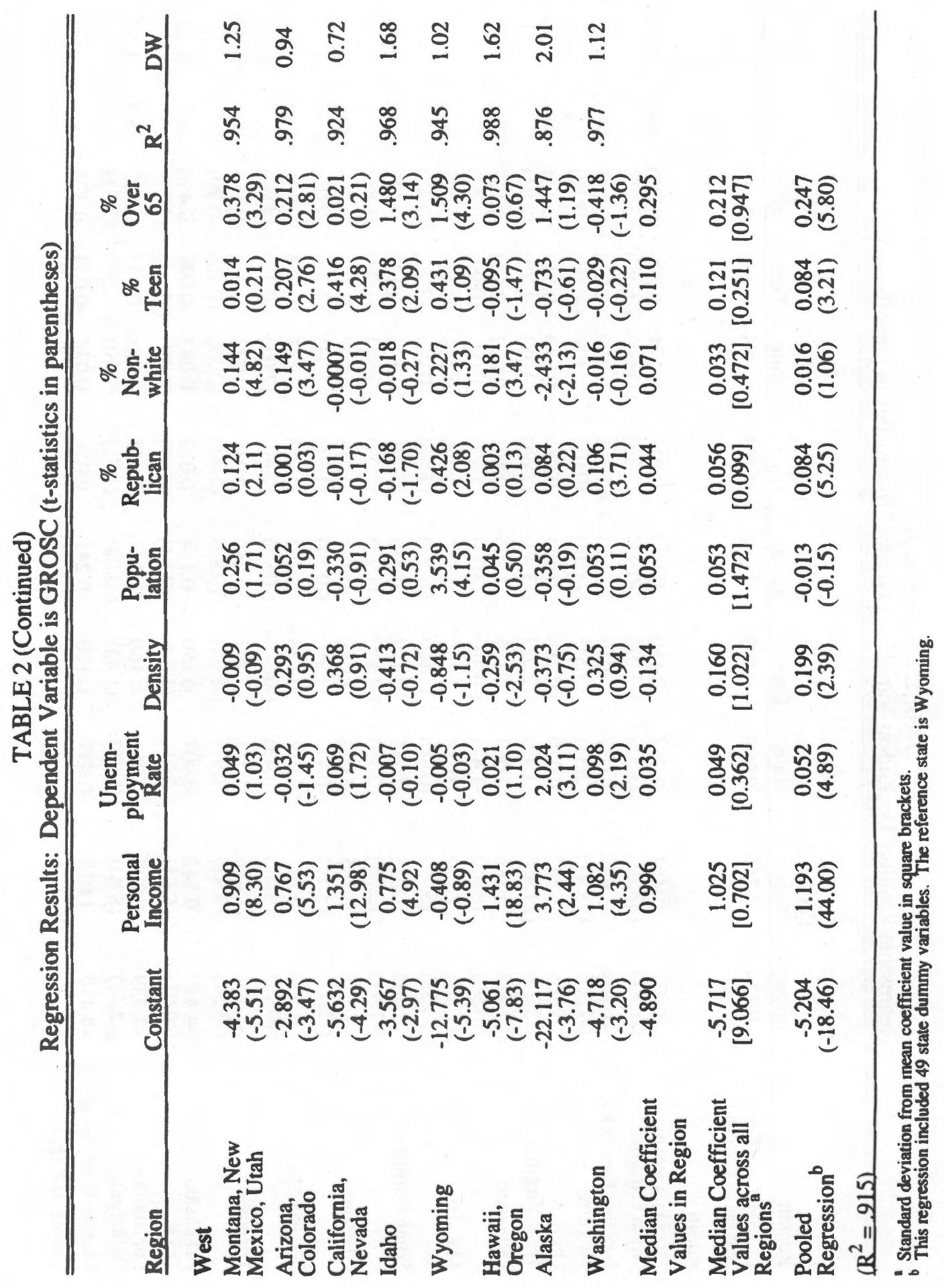


\%Teen suggests that a 10 percent increase in the variable is associated with a 1.2 percent increase in GROSC across the states, reflecting a greater need for expenditure on education the greater the fraction of population that is young. Eighteen of the coefficients are positive and, among these, eleven are significant at the .05 level or better (using a two-tailed test). Among the thirteen states or subregions with negative coefficients, only two have statistically significant values for this variable. Unusually high values for this coefficient are found in the cases of Massachusetts/New Hampshire, Rhode Island, New Jersey/New York, Maryland, Idaho, Wyoming, and California/Nevada. Thus state taxes, and presumably state expenditures, grew at a very fast clip in these latter states during the height of the baby-boom. Examination of regional medians for this variable suggests that per capita revenues in the South are unresponsive, if not inversely related, to the level of this variable. States in the Northeast, on the other hand, exhibit the greatest elasticities in this regard.

Like the regression coefficients on \%Teen, one also finds the coefficients of percent of population aged 65 and over to be generally positive (there are thirteen cases in which the coefficient is positive and significant at the .05 level or greater). The median coefficient value indicates that more than a 2 percent increase in per capita revenue is associated with a $10 \%$ increase in the proportion of the population aged 65 and over. The magnitude of this coefficient, therefore, is somewhat larger than that found for \%Teen. The positive values found for the coefficient may reflect a stronger taste among an older population for public goods and services or may be reflective of an older population attracting a greater amount of business to a state and therefore a greater need for publicly provided services. Conversely, Missouri and the three-state region consisting of Florida, Georgia, and North Carolina all possess highly significant, negative coefficients for this variable. The negative coefficient in these cases may be reflective of a population that has become more fiscally conservative as it has aged.

On significance grounds, $\%$ of working age population that is non-white is the weakest taste variable included in the model. The variable is positive and significant at the .05 level or greater in eight instances and negative and significant in four other instances. The median value of the estimated coefficient is virtually zero. Examination of significant coefficients (positive and negative) reveals no clear-cut regional patterns, though the median value for the North Central region is highest at .135 .

State unemployment rate is statistically significant in a large number of cases (15), but, perhaps running against the grain of conventional wisdom, is uniformly positive in these instances. The median value of the coefficient suggests that per capita revenues rise with unemployment, though the magnitude of the coefficient, at .049, appears to be small. The largest values for this coefficient are found in the 
Northeast (.118). Although this coefficient median appears to be small, swings in the unemployment rate in percent terms are large over the course of the business cycle. For example, the mean unemployment rate in our sample is approximately 6 percent. A two percentage point increase in the unemployment rate, which might easily occur during a recession, amounts to a 33 percent change in the variable. Thus the elasticity coefficient implies a fairly substantial 3.9 percent increase in per capita revenue in the Northeast when the unemployment rate changes by two percentage points from its mean value. One might expect revenues to fall in periods of high unemployment, as many state and local taxes are income driven. It must be remembered here, however, that the analysis is conducted under ceteris paribus conditions and therefore the positive values of these coefficients reflect to some degree an equilibrium phenomenon. That is, at a given level of income, as unemployment rises, the need for publicly provided goods and services rises also. States in the face of rising unemployment will naturally have to provide more goods and services to residents in the form of unemployment compensation, job training, education, and so forth. This higher level of public support bears with it a price tag in the form of higher taxes. ${ }^{25}$

Significant coefficient values on percent voting Republican in the presidential election are all positive (there are 10 altogether). One typically thinks of the Republican party as the party of fiscal conservatism. Based on this line of reasoning, we expected to find lower levels of per capita state and local tax revenues collected in areas heavily voting Republican in presidential elections. The median value of this coefficient is only .056 , however, indicating the relationship, though direct in a few instances, is quite weak. ${ }^{26}$

Turning to the variables included as scale measures, we find the results on population density somewhat inconsistent with the hypothesis advanced above. That is, in the cases where the variable is statistically significant, the majority ( 8 out of 13) are positive. Furthermore, the median value of the coefficient is .16, suggesting modest increases in per capita state revenue as population density increases. Thus density, rather than reflecting economies of scale in provision of public goods and services, acts as a proxy for urbanization in many cases and is associated with greater need for public goods and services in urban settings because of problems such as congestion, crime, and air pollution. Regionally, one finds considerable diversity among the median coefficient values. The median is particularly large for the North Central region. The median coefficient value in the West, however, is negative, suggesting that states in this region may indeed be able to take advantage of scale economies in the provision of public goods and services.

We find that population growth is associated with higher levels of state and local tax revenues on a per capita basis about as often as it is associated with 
lower levels of state and local per capita revenues (seven of twelve statistically significant coefficients are positive). Since density is being held constant, a growing population is reflected in growth in outlying areas. Hence the transportation costs necessary to deliver public goods and services rise, and the unit cost of production is increased. Increases in population may also be an indication of faster economic growth (via in-migration), which also contributes to increases in GROSC through adjustment costs. The median value of the coefficient, at .053 , suggests a fairly weak elasticity of revenue with respect to size of the population, but this value belies considerable regional diversity in the coefficient's value. For example, Rhode Island, Pennsylvania, Wisconsin, Nebraska, Delaware, and Wyoming all have elasticities greater than one. Other states, such as Massachusetts/New Hampshire, Illinois, Maryland, Indiana/Kentucky/Virginia, and North Dakota/South Dakota, have elasticities below -1, suggesting that these states have been able to realize scale economies in the provision of public goods and services.

Finally, the median value of the constant terms is -5.717 . The differences in the constant terms (i.e, the fixed effects) suggest considerable differences in per capita revenue levels across the states holding the explanatory variables constant. The standard deviation of the constants is substantial at 9.066. The magnitude of the constant term may be a reflection of the underlying commitment of state and local governments to provide for the basic needs of their constituents. ${ }^{27}$ The larger the constant, the stronger the commitment. It is likely that the fixed effects also reflect to some degree unmeasured differences in cost of living across states. $^{28}$

\section{v. CONCLUSION}

This paper has investigated the determinants of state and local revenues from own sources, allowing for differences among the states in the way the explanatory variables affect the dependent variable. We find that allowing for such heterogeneity is very important and, indeed, that not allowing for this heterogeneity would mask considerable diversity among the states in the way in which revenues are determined. This diversity may go far in explaining the high degree of migration of people and businesses. In other words, as the Tiebout hypothesis would predict, because of differing tastes and preferences, economic agents continually sort themselves to locations they find to be advantageous.

Although we find substantial diversity among the states in the way in which revenues are determined, we also find, using the selective pooling procedure, that there is some degree of homogeneity within smaller subregions of the states. 
Noteworthy in this regard are the New England, West North Central, West South Central, and Mountain regions. Hence the results certainly provide some degree of evidence to support the existence of neighboring state behavior with respect to tax policy among the states.

Our most consistent regression result concerns the relation between income and tax revenue. Here we find a strong positive relationship with an elasticity above one in a majority of regressions, indicating tax structures are fairly responsive to economic growth in most states. Whether this elasticity exceeds one is indicative of the taxpayers' willingness to pay for more and/or better public services as personal income rises.

Finally, we believe a fruitful area for future research will be to examine the same issues that we have addressed here on the expenditure side of the budget. For example, does one find similar groupings among the states when per capita expenditure is used as the dependent variable? One might also disaggregate total expenditures by type and examine the degree of heterogeneity among the states. A particularly interesting question to ask in this regard is whether neighboring state behavior takes place with respect to expenditures on education. It would surely seem so, as one observes a good deal of mobility, at least within a state, across school district lines as parents seek out communities with good schools for the education of their children. The question, then, is whether similar forces are at work across states. If so, then one would expect to see neighboring state behavior taking place among the states with respect to educational expenditure.

\section{ENDNOTES}

1. Mills and Hamilton (1994) argue that state and local government revenues should be combined because "... it is very difficult to obtain comparable data on state and local public finances. The fact, for example, that one state government has a much smaller budget than another may simply mean that municipalities in the first state finance services that are financed by state government in the other."

2. See the studies by Gold $(1983,1987)$, Mieszkowski and Stein (1983), and Izraeli (1993). Other studies have concentrated on state differences in business taxes (Wheaton 1983) and in income taxes (Hunter and Scott 1986). The study by Gade and Adkins (1990) focuses on the tax exporting effect that federal deductibility provisions have on state tax structures.

3. Specifically, we employ a series of Chow tests to identify subnational groupings of states possessing homogeneous regression coefficients.

4. To our knowledge there has been only one previous attempt to measure the neighboring state effect (Case, et. al. 1989). The approach we employ, how- 
ever, is quite different in that we restrict possible occurrences of the neighboring state effect to cases in which states literally are neighbors in the geographic sense. We choose to test for homogeneity on the basis of geographic proximity for the reasons detailed in the text above. Homogeneity may occur for reasons other than geographic proximity, but exploration of these other factors is beyond the scope of this study.

5. Musgrave and Musgrave (1989) state: "A first approximation to fiscal capacity is given by per capita income."

6. Gold (1983) estimated the income elasticity of tax revenues to be between 1.4 and 2.0 .

7. Gold (1983) estimated the income elasticity of sales tax revenues (general) to be between .9 and 1.1. (He found, however, that the elasticity for selective sales taxes was much smaller.)

8. Although general sales tax applies to consumers' goods as well as producers' goods, the consumers' share is 59 percent for all states. (Ring 1989).

9. Examples of such changes are variations in the amount of exemption, in the cap on total revenue, and in the level of tax rates. As a result, the magnitude, or possibly even the sign, of the correlation between income and tax revenues may change. They may do so either because of political reasons or economic reasons or because of both.

10. Note that there are interstate differences in the tax structure. In 1987, for example, seven states did not have an individual income tax.

11. In this context, we believe that the interpretation of a negative elasticity should be as follows: As income increases, people switch from consumption of public services to private ones; e.g., instead of public schools, they prefer private schools.

12. Since various states use different tax structures, the comparison of tax burdens is not an easy task. In particular, an official tax rate is not necessarily the best indicator to be used for such a comparison because the base it applies to differs by states due to exemptions, tax credits, deductions, and other special treatments.

13. On the basis of some initial experimentation, we decided to use the log$\log$ functional form in the empirical analysis reported below. This functional form has the side benefit that the regression coefficients are elasticities.

14. This is not to rule out other possible grounds on which to group states, but it does strike us as the most logical criterion. Case, Hines, and Rosen (1989), for example, using an approach markedly different from ours, group states on the basis of geography, but also on the basis of income level and racial composition. Interestingly, their best results obtain when they group on the basis of racial composition. 
15. This procedure was first used in an analysis of state unemployment rates by Murphy and Hofler (1984).

16. The Census subregions are defined as follows:

New England--Connecticut, Maine, Massachusetts, New Hampshire,

Rhode Island, Vermont.

Mid Atlantic--New Jersey, New York, Pennsylvania.

East North Central--Illinois, Indiana, Michigan, Ohio, Wisconsin.

West North Central--Iowa, Kansas, Minnesota, Missouri, Nebraska, North Dakota, South Dakota.

South Atlantic--Delaware, Florida, Georgia, Maryland, North Carolina,

South Carolina, Virginia, West Virginia.

East South Central--Alabama, Kentucky, Mississippi, Tennessee.

West South Central--Arkansas, Louisiana, Oklahoma, Texas.

Mountain--Arizona, Colorado, Idaho, Montana, Nevada, New Mexico, Utah, Wyoming.

Pacific--Alaska, California, Hawaii, Oregon, Washington.

17. The null hypothesis is that the regression coefficients in a given grouping of states are identical across those states. Non-rejection of the null hypothesis results in maintaining the grouping of the states. The form of the test statistic is:

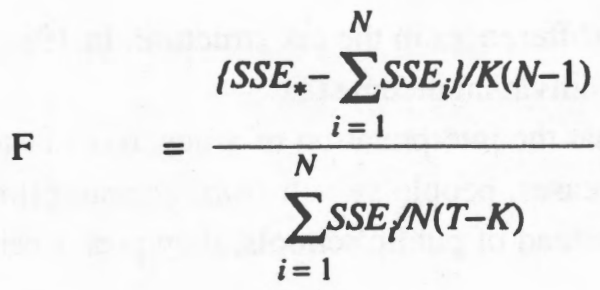

where $\quad$ SSE $*$ is the sum of squared errors from the pooled regression; $\mathrm{SSE}_{\mathrm{i}}$ is the sum of squared errors from state i's regression;

$\mathrm{N}$ is the number of states in the grouping;

$T$ is the number of years;

and $\quad \mathrm{K}$ is the number of estimated parameters in the regression.

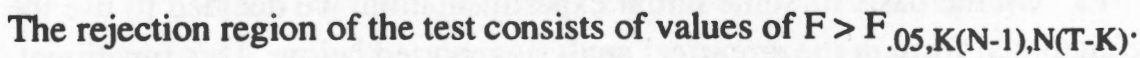

18. This restriction seemed reasonable, given the criterion of geographic proximity, and given the practical need to keep possible combinations considered to manageable proportions.

19. Alternatively, one could divide per capita state and local revenue by per capita income to obtain a tax rate for each state and use this measure as the dependent variable. Because we employ a log-log functional form with income on 
the right hand side, however, this approach is essentially equivalent to the procedure that we use.

20. An anonymous referee points out that the literature on business location indicates that causality runs in the opposite direction, i.e., from taxes to income. To the extent this is a problem, the regression results may be confounded to some degree by simultaneity bias.

21. Both the per capita personal income and the per capita revenue variable (GROSC) are deflated by the consumer price index with base years 1982-84.

22. Percent voting Republican in the last presidential election standardizes across states for attitude to a greater degree than other political variables such as percent voting Republican for governor. The problem with the latter is that some Republican governors are more liberal than some Democratic governors. The Republican presidential candidate, on the other hand, represents essentially the same package of political proposals and philosophy to voters across all states.

23. Ideally, we would have liked to use an urbanization rate variable to measure the economy of scale effect; however, this variable is available by state during census years only. The population density variable, which is available in all years of our sample, is used as a proxy for rate of urbanization.

24. The results from this regression are reported at the bottom of Table 2.

25. This development is mostly the result of the inability of state and local governments to create (print) new money. Even during hard times they have to raise additional revenues in order to pay for additional expenditures.

26. An alternative explanation, suggested by an anonymous referee, is that high tax states may vote Republican disproportionately, reflecting growing opposition to higher taxes and sentiment in favor of tax reduction.

27. In studies of geographic differences in unemployment rates, differences in the fixed effects are interpreted as reflecting differences in frictional unemployment across labor markets [Brechling (1967), Fearn (1975), Hyclak and Lynch (1980), and Murphy and Hofler (1984)].

28. In order to determine the degree to which federal transfers might affect our results, we also applied the selective pooling procedure to an alternative dependent variable, per capita revenue, including transfers from the federal government. We found broad similarities among the two sets of results, with the significant exceptions to this conclusion being that population density appears to have a substantively different impact depending on which dependent variable was used, that changes in the unemployment rate have a weaker impact on own state revenues than on gross state revenues, and that the income elasticity is somewhat stronger when gross state revenue is used as the dependent variable. These differences suggest that the federal government may not be completely neutral with 
respect to revenue across states. These additional regression results are available to the interested reader upon request.

\section{REFERENCES}

Brechling, Frank. "Trends and Cycles in British Regional Unemployment." Oxford Economic Papers 19 (1) (1967): 1-21.

Case, Anne C., James R. Hines, Jr., Harvey S. Rosen. "Copycatting: Fiscal Policies of States and Their Neighbors." NBER Working Paper, \#3032, July 1989.

Fearn, Robert. "Cyclical, Seasonal, and Structural Factors in Area Unemployment Rates." Industrial and Labor Relations Review 28 (3) (1975): 424-431.

Gade, Mary N., and Lee C. Adkins. "Tax Exporting and State Revenue Structures." National Tax Journal, 43 (1) (1990): 39-52.

Gold, Steven D. "Recent Developments in State Finances." National Tax Journal 36 (1) (1983): 1-29.

"Developments in State Finances, 1983 to 1986." Public Budgeting and Finance (Spring 1987): 5-23.

Hunter, William J., and Charles E. Scott. "Interstate Differences in Individual Income Taxes." Public Finance Quarterly 14 (1) (1986): 69-85.

Hyclak, Thomas, and Gerald Lynch. "An Empirical Analysis of State Unemployment Rates in the 1970s." Journal of Regional Science 20 (3) (1980): 377386.

Izraeli, Oded. "Interstate Differences in State and Local Revenues Per Capita." Growth and Change 24 (1) (1991): 51-66.

Mieszkowski, Peter, and Robert M. Stein. "Trends and Prospects in State and Local Finance." Journal of Urban Economics 14 (1983): 224-241.

Mills, Edwin, and Bruce W. Hamilton. Urban Economics, 5th ed. New York: Harper-Collins, 1994.

Murphy, Kevin J., and Richard A. Hofler. "Determinants of Geographic Unemployment Rates: A Selectively Pooled--Simultaneous Model." The Review of Economics and Statistics 56 (2) (1984): 216-223.

Musgrave, Richard A., and Peggy B. Musgrave. Public Finance in Theory and Practice, 5th edition. New York: McGraw-Hill Book Co., 1989.

Oates, Wallace. "Searching for Leviathan: An Empirical Study." American Economic Review 75 (4) (1985): 748-757.

Ring, Raymond J., Jr. "The Proportion of Consumers' and Producers' Goods in the General Sales Tax." National Tax Journal 42 (2) (1989): 167-79. 
Wheaton, William C. "Interstate Differences in the Level of Business Taxation." National Tax Journal, 36 (1) (1983): 83-94.

U.S. Department of Commerce, Bureau of Census. U.S. Census of Population, state volumes, 1960, 1970, and 1980.

. Government Finances, various years.

. Statistical Abstract, various years.

U.S. Department of Labor, Bureau of Labor Statistics. Geographic Profile of Employment and Unemployment, various years. 